\title{
Hereditary Breast-Ovarian Cancer Team of the University Medical Centre Groningen (UMCG) - a Report
}

\author{
Marian J.E. Mourits', Jan C. Oosterwijk², Jakob de Vries ${ }^{3}$ \\ 1Dept. of Gynaecologic Oncology; ${ }^{2}$ Dept. of Medical Genetics; ${ }^{3}$ Dept. of Surgical Oncology, University Medical Centre Groningen (UMCG), University of Groningen, \\ The Netherlands
}

Corresponding author: Marian J.E. Mourits, MD PhD, Dept. of Gynaecologic Oncology, University Medical Centre Groningen (UMCG), University of Groningen, Hanzeplein 1, 9700 RB, The Netherlands

Submitted: 1 November 2005

Accepted: 10 November 2005

Female carriers of a germline BRCA1 or BRCA2 mutation have a cumulative lifetime ovarian cancer risk of $39-54 \%$ or $11-23 \%$, respectively $[1,2]$. Preventive health strategies for these women include gynaecological screening aiming at early cancer detection and prophylactic salpingo-ophorectomy aiming at cancer risk reduction. However, it is becoming increasingly clear that (bi) annual gynaecological screening by transvaginal ultrasonography and serum CA125 estimation in women at increased risk of ovarian cancer is ineffective in detecting presymptomatic ovarian cancer [4]. In a recent publication a positive predictive value of $17 \%$ and a sensitivity of less than $50 \%$ were found for screening for ovarian cancer in a high-risk population [3]. Preventive bilateral salpingo-oophorectomy (BSO) reduces ovarian cancer risk by $96 \%$ and breast cancer risk by $50 \%$ or less, depending on the age of preventive surgery. Preventive $\mathrm{BSO}$ at a premenopausal age is the most effective strategy to prolong life in the case of a BRCA1 mutation [5]. In our clinic, we therefore counsel women with a BRCA1/2 gene mutation to choose preventive surgery after childbearing age. From the age of 35-40 for BRCA1 mutation carriers and from the age of 40-45 for BRCA2 mutation carriers, these women are advised to undergo a laparoscopic BSO. Counselling is provided at our multidisciplinary outpatient clinic by an experienced gynaecologist who discusses the benefits and drawbacks of the decision for or against preventive surgery with the patient and the (contra) indications for hormonal replacement therapy (HRT). Additional psychological counselling is available from the team's psychologist. In our clinic, uptake of preventive BSO is more than $70 \%$ in the total group of counselled mutation carriers and rises to more than $90 \%$ in women by the time they reach the age of 50 years.

The operation is performed in a day care setting and starts with peritoneal washing for a cytologic examination to detect subclinical (extra) ovarian or tubal cancer, followed by BSO. Atraumatic tissue handling is performed by grasping the ovarian pedicles instead of the ovarian epithelium. The fallopian tube is removed from the uterine corner by bipolar coagulation and only the intramural part of the tube is left in situ. After marking one adnex, the adnexa are taken out of the body by an endobag. The tissue is sent for histopathological examination.

Since the publications of case reports linking BRCA mutations to an increased risk of fallopian tube cancer as well, preventive oophorectomy is recommended to be replaced by $\mathrm{BSO}$ [6]. Although the rationale for removing the total fallopian tube by removing the uterus as well is clear, we could not find any evidence that a hysterectomy adds to reducing the risk of fallopian tube cancer more than a complete BSO alone. In a large clinicopathologic study of 105 cases of fallopian tube cancer, $92 \%$ were situated in the tubal portion, most often the distal part, while $8 \%$ were confined to the fimbriae [7].

Following preventive $\mathrm{BSO}$, women who are younger than 45 years of age and have no history of breast cancer are counselled to use HRT, to treat vasomotor symptoms 
and sexual side effects of oestrogen deprivation. In the case of prescription of HRT, we prescribe tibolone, because in contrast to oestrogen/progestogen treatment, it appears to exert little stimulation of breast tissue and does not increase the mammographic breast density [8].

Women who have been treated for breast cancer, or are older than 45-50 years of age, are advised not to use HRT. In the case of severe vasomotor symptoms, non-hormonal treatment is proposed by selective serotonin reuptake inhibitors (SSRI).

\section{References}

1. Antoniou A, Pharoah PD, Narod S, Risch HA, Eyfiord JE, Hopper JL, Loman N, Olsson H, Johannsson O, Borg A, Pasini B, Radice P, Manoukian S, Eccles DM, Tang N, Olah E, Anton-Culver H, Warner E, Lubinski J, Gronwald J, Gorski B, Tulinius H, Thorlacius S, Eerola $H$, Nevanlinna H, Syrjakoski K, Kallioniemi OP, Thompson D, Evans C, Peto J, Lalloo F, Evans DG and Easton DF. Average risks of breast and ovarian cancer associated with BRCA1 or BRCA2 mutations detected in case series unselected for family history. A combined analysis of 22 studies. Am J Hum Genet 2003; 72: $1117-1130$.

2. King MC, Marks JH, Mandell JB; New York Breast Cancer Study Group. Breast and ovarian cancer risks due to inherited mutations in BRCA1 and BRCA2. Science 2003; 302: 643-646.

3. Stirling D, Evans DG, Pichert G, Shenton A, Kirk EN, Rimmer S, Steel CM, Lawson S, Busby-Earle RM, Walker J, Lalloo Fl, Eccles DM, Lucassen AM and Porteous ME. Screening for familial ovarian cancer: failure of current protocols to detect ovarian cancer at an early stage according to the international Federation of gynecology and obstetrics system. J Clin Oncol 2005; 23: 5588-5596.

4. Vasen HF, Tesfay E, Boonstra H, Mourits MJ, Rutgers E, Verheyen R, Oosterwijk J, Beex L. Early detection of breast and ovarian cancer in families with BRCA mutations. Eur J Cancer 2005; 41 (4): 549-554.

5. van Roosmalen MS, Verhoef LC, Stalmeier PF, Hoogerbrugge N, van Daal WA. Decision analysis of prophylactic surgery or screening for BRCA1 mutation carriers: a more prominent role for oophorectomy. J Clin Oncol 2002; 20: 2092-2100.

6. Zweemer RP, van Diest PJ, Verheijen RH, Ryan A, Gille JJ, Sijmons $\mathrm{RH}$, Jacobs IJ, Menko FH and Kenemans P. Molecular evidence linking primary cancer of the fallopian tube to BRCA1 germline mutations. Gynecol Oncol 2000; 76: 45-50.

7. Alvarado-Cabrero I, Young RH, Vamvakas EC and Scully RE. Carcinoma of the fallopian tube: a clinicopathological study of 105 cases with observations on staging and prognostic factors. Gynecol Oncol 1999; 72: 367-379.

8. Lundstrom E, Christow A, Kersemaekers W, Svane G, Azavedo E, Soderqvist G, Mol-Arts M, Barkfeldt J and von Schoultz B. Effects of tibolone and continuous combined hormone replacement therapy on mammographic breast density. Am J Obstet Gynecol 2002; 186: 717-722.

9. Loprinzi CL, Kugler JW, Sloan JA, Mailliard JA, LaVasseur BI, Barton DL, Novotny PJ, Dakhil SR, Rodger K, Rummans TA and Christensen BJ. Venlafaxine in management of hot flashes in survivors of breast cancer: a randomised controlled trial. Lancet 2000; 356: 2059-2063. 